\section{Butterfly origin}

The British Butterflies: Their Origin and Establishment. By R. L. H. Dennis. Pp. xviii +318. (E. W. Classey: Faringdon, UK, 1977.) £10.

THE message of this book is simple: recent work on the British Pleistocene suggests that all Britain's butterflies must have been exterminated by cold before the amelioration of climate which began 10-15,000 yr ago; no existing populations of butterfiles in the British Isles, including various endemic "subspecies", can be older than that. This view contrasts with the earlier ideas of B. P. Beirne and E. B. Ford, who, working with a radically different and now outmoded reconstruction of Pleistocene events, considered that at least some of our butterflies had existed continuously in Britain for $100,000 \mathrm{yr}$ or more. Dennis's book has some subsidiary themes, one being that phenotypic divergence of a butterfly population bears no direct relationship to either its antiquity or total genetic divergence. I agree with both of these conclusions.

Dennis's treatment of the subject is based on a wide reading of the work on the Pleistocene, local literature pertaining to the distribution and ecology of British butterflies, and an eclectic selection of genetical texts. Two extremely relevant areas of work are completely ignored: MacArthur-Wilson island biogeography theory, aspects of which Dennis apparently rediscovers for himself, and Paul Ehrlich's school of work on Euphydryas colony structure. He does refer once to the classic paper of Ehrlich and Raven on butterfly and plant coevolution. In doing so, he misspells Erlich (sic), gives the wrong publication date, and apparently misunderstands the particular ideas of biochemical coevolution involved. Further, in discussing phenotypic divergence, antiquity and evolutionary rates, Dennis makes no reference to work on rates of protein evolution.

If the essential message of the book is simple, and key areas of the literature have been ignored, why does Dennis's main text span 270 close-set pages? Because he frequently uses whole sentences where one word (or even none!) would suffice. $\mathrm{He}$ is at pains at every point to indicate that he has thought of every possibility. He attacks the same problems again and again, using the very few lines of evidence open to him. As a result, instead of being a delightful natural history detective story, the book is bewildering. Alternative hypatheses are not presented and dealt with in a logical way, step by step. Instead, we are fed with an unending torrent of jargon-laden fact, theory and specula- tion, leaving the reader in a state of dizzying confusion. Beneath this, many of Dennis's ideas are sound, and one gets an impression of tremendous enthusiasm. If so, it is unfortunate that the book has been published in its present, clearly unedited state, because both the author and his intended audience are the losers.

In short, although it will have some value as a reference source, and for Dennis's original contributions on the analysis of distribution, I cannot recummend this as a good book. I looked forward with keen anticipation to reading it, which is perhaps partly why I find it disappointing. But it is the language which really spoils it. For example, on p243 we are told that "Bearing in mind the reticulate control pathways of atmospheric inputs

\section{Chemical dynamics}

Dynamics of Molecular Collisions. Parts A and B. Modern Theoretical Chemistry. Vol. 1. Pp. 318. \$39.50. Vol. 2. Pp. 380. $\$ 47.40$. Edited by W. H. Miller. (Plenum: New York and London, 1977).

IN the past fifteen years, there has been much progress in the field now known as chemical dynamics. The development of the crossed-molecular-beam technique provided a means of studying chemical reactions in more detail, and many new and powerful experimental techniques are now being used in this area. It is now reasonable to ask an ultimate question in kinetics: what is the cross-section for scattering at a particular angle from each state $i$ of species $A$ to every state $f$ of a product $B$ at any relative energy? This experimental activity has led chemists into scattering theory; previously, this had been a province of physics. New theoretical techniques and models have been developed by chemists for handling molecular collisions, and some of these are now finding applications in certain areas of physics.

These first two volumes in the series Modern Theoretical Chemistry contain thirteen chapters, each by a different author, on theoretical techniques that are appropriate for describing chemical dynamics. The first, by W. A. Lester, $\mathrm{Jr}$, is on the $N$ coupled-channel problem. The author likens coupledchannel methods to $a b$ initio computations of molecular properties, for they provide a source of reliable data in cases where experiments may be difficult and they serve as a test of approximate methods. The second, by $\mathrm{H}$. Rabitz, is devoted to effective Hamiltonians; it describes various means of reducing the number of rotational into local ecosystems, and the original and ultimate dependence of contemporary environments on atmospheric influences, though modified by the interaction of living and non-living components, and thus, in the attempt, to avoid recourse to simplistic determinism, it is suggested that the increasing assumption of oceanic conditions to the north and west of Britain has resulted in a primary structure of selection gradients." Such gems of egregious obfuscation abound throughout the whole work. Onily the dedicated will probe below this forbidding mask.

R. I. Vane-Wright

R. I. Vane-Wright is Head of the ButterNy Section at the British Museum JNatural History).

channels that need to be considered explicitly. There is a chapter by $\mathrm{D}$. A. Micha on the use of optical potentials in molecular collisions-their name comes from the analogy between the wave-mechanical aspects of molecular collisions and electromagnetic propagation in an inhomogeneous medium with a complex index of refraction. There is a chapter on vibrational energy transfer by $H$. K. Shin, and one on the scattering of atoms and molecules from solid surfaces by G. Wolken, Jr. The final chapter in Part $A$ is a very clear account of the theory of nonradiative processes by $W$. Siebrand.

Part B contains articles on classical and semi-classical methods. It begins with a chapter on classical trajectory methods by $\mathbf{R}$. N. Porter and L. M. Raff. The second chapter, by P. J. Kuntz, is an excellent account of the effect of features of the potential energy surface on molecular collisions. The third chapter, by W. L. Hase, is concerned with the dynamics of unimolecular reactions, and in particular with the RRKM theory. M. S. Child contributes a useful chapter on semiclassical methods and J. C. Tully writes on non-adiabatic processes in molecular collisions. The sixth chapter, by P. Pechukas, is on statistical approximations in collision theory, that is, on the transition-state theory. The final chapter, by R. D. Levine and R. B. Bernstein, is on the thermodynamic approach to collisions; it makes use of information theory.

The topics have been well selected and the authors are known for their work in the field. These two volumes will be very useful to research workers entering the field.

A. D. Buckingham

A. D. Buckingham is Professor of Chemistry at the University of Cambridge, UK. 